\title{
KUALITAS REPAIR WELDING DENGAN METODE OXY-ACITELYN PADA CAST WHEEL ALUMINIUM
}

\author{
Budi Harjanto \\ Pendidikan Teknik Mesin FKIP Universitas Sebelas Maret \\ Kampus V UNS Jl. Ahmad Yani 200 Pabelan Surakarta \\ Telp 0271 718419, Fax 0271718419 \\ E-mail: inibudi@fkip.uns.ac.id
}

\begin{abstract}
ABSTRAK
Penelitian yang telah dilakukan adalah reparasi cast wheel (velg) aluminium yang sudah mengalami kerusakan (retak) dengan metode pengelasan Oksi-Asitelin. Pengelasan pada velg berbahan Aluminium memungkinkan digunakan untuk memperbaiki kerusakan sejauh kekuatan sambungan las tersebut mendekati kekuatan dari velg utuh.

Sebelum percobaan pengelasan Oksi-Asitelin dilakukan, maka dilakukan dahulu beberapa pengujian untuk mengetahui data awal. Pengujian bertujuan untuk mengetahui kondisi material asli (base material). Dari pengujian awal diperoleh bahwa material asli adalah Al-7,3\%Si yang memiliki kekerasan sebesar 57,63 HBN dan memiliki kekuatan impak sebesar $0,108 \mathrm{Joule} / \mathrm{mm}^{2}$. Data yang diperoleh pada pengujian tersebut merupakan data acuan untuk menjadi pembanding hasil percobaan dengan pengelasan Oksi-Asitelin.

Hasil uji kekerasan proses pengelasan Oksi-Asitelin untuk daerah perbatasan antara logam induk dan logam lasan adalah 38,69 BHN sedangkan pada logam lasan sebesar 54,80 BHN..Hasil uji impak untuk pengelasan Oksi-Asitelin sebesar $0,085 \mathrm{Joule} / \mathrm{mm}^{2}$.

Dari hasi pengujian kekerasan dan impak dapat diketahui bahwa nilai kekerasan dan kekuatan impak hasil lasan masih lebih kecil dibandingkan dengan kekerasan dan kekuatan impak logam induk. Hal ini berarti bahwa hasil pengelasan belum layak digunakan, karena nilai kekerasan dari hasil pengelasan belum mendekati nilai kekerasan logam induk.
\end{abstract}

Keywords: Pengelasan Oksi-Asitelin, Al-7,3\%Si

\section{PENDAHULUAN}

Cast wheel (velg) mobil merupakan salah satu bagian dari mobil yang berfungsi untuk menumpu ban roda pada kendaraan. Pada saat mobil melaju kencang, benturan yang keras di bagian roda mungkin saja terjadi, akibat roda melindas jalan berlubang maupun jalan yang bergelombang. Akibat benturan yang terjadi berulang-ulang ini, velg mobil dapat mengalami keretakan pada bagian tertentu. Jika dibiarkan, lama kelamaan retak pada velg mobil akan menjalar dan akan menyebabkan patah. Akibatnya kecelakaan fatal dapat saja terjadi saat mobil melaju dengan kencang. Namun jika masih memungkinkan, retak yang terjadi pada velg dapat diperbaiki dengan cara pengelasan, sehingga dapat menghemat biaya.

Pengelasan pada cast wheel (velg) berbahan aluminium memungkinkan digunakan untuk memperbaiki kerusakan sejauh kekuatan sambungan las tersebut mendekati kekuatan dari velg utuh. Pada penelitian ini digunakan pengelasan Oksi-Asitelin.

\section{LANDASAN TEORI}

Menurut Deutsche Industrie Normen (DIN) las adalah ikatan metalurgi pada sambungan logam paduan yang dilaksanakan dalam keadan cair. Proses pengelasan akan mengakibatkan logam di sekitar lasan mengalami siklus termal berupa pemanasan sampai temperatur maksimum, dengan di ikuti pendinginan sehingga menyebabkan terjadinya perubahan-perubahan metalurgi dan deformasi.

Sebelum melakukan pengelasan, ada beberapa prinsip dasar yang harus dipahami tentang bahan aluminium tersebut. Hal terpenting adalah tentang tingginya titik leleh yang bisa menyebabkan terbentuknya lapisan oksida pada permukaan logam akibat panas yang ditimbulkan dari operasi pengelasan. Lapisan oksida tersebut harus dihilangkan sebelum dilakukan pengelasan-pengelasan berikutnya. 
Hasil pengelasan aluminium rentan terhadap berbagai macam cacat cracking. Kecenderungan terbentuknya solidification cracking berkaitan langsung dengan perbedaan antara suhu solidus dan likuidus dari logam aluminium.

\section{Las Oksi-Asitelin (Oxy-acetilyn Welding)}

Pada las oksi-asitelin, panas dihasilkan dari reaksi pembakaran anatara gas asitelin dengan oksigen. Nyala yang dihasilkan terdiri dari dari 2 daerah/zona, yaitu:

- Daerah pembakaran primer (primary combution)

Menghasilkan panas sekitar 1/3 dari total panas pembakaran sempurna.
$\mathrm{C}_{2} \mathrm{H}_{2}+\mathrm{O}_{2}($ Silinder $)=2 \mathrm{CO}+\mathrm{H}_{2}$

- Daerah pembakaran sekunder yang terjadi setelah pembakaran primer berlangsung

$$
\begin{aligned}
& \left.2 \mathrm{CO}+\mathrm{O}_{2} \text { (atmosfir }\right)=2 \mathrm{CO} \\
& \left.\mathrm{H}_{2}+\frac{1}{2} \mathrm{O}_{2} \text { (atmosfir }\right)=\mathrm{H}_{2} \mathrm{O}
\end{aligned}
$$

\section{HASIL DAN PEMBAHASAN a. Uji Komposisi Kimia}

Setelah dilakukan pengujian komposisi kimia terhadap base material dari velg aluminium didapatkan komposisi sebagai berikut:

\section{A $\quad$ St $\quad$ Fo

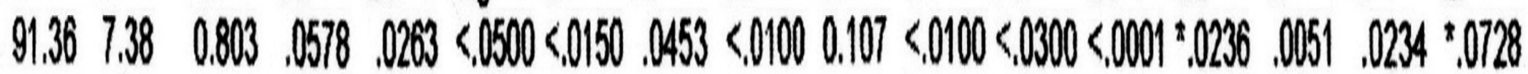

\section{b. Pengujian Kekerasan} didapatkan

Dari hasil pengujian kekerasan

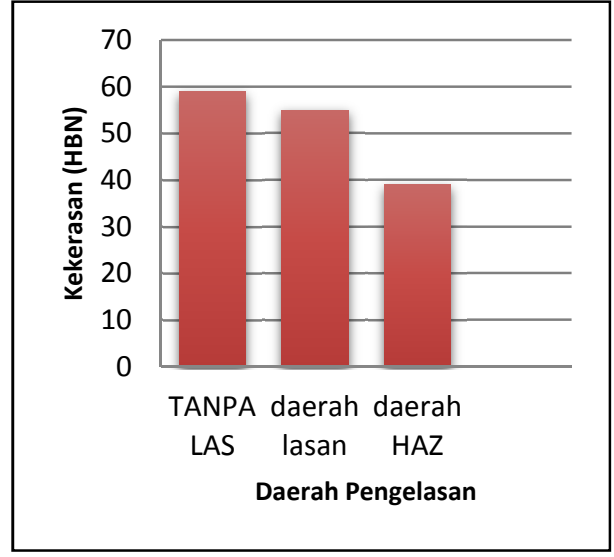

Gambar 2 . Diagram Nilai Kekerasan pada

\section{Sambungan Las}

Dari diagram diatas terlihat bahwa di daerah pengelasan material yang dilas dengan Las Oksi-Asitelin memiliki kekerasan 54.80 HBN dan daerah perbatasan memiliki kekerasan sebesar 38.69 sedangkan base material memiliki kekerasan 59.59 HBN. Ini berarti dari proses pengelasan seperti yang dilakukan diatas masih memiliki nilai kekerasan yang lebih rendah dari base material yang tanpa mengalami proses pengelasan. isi kimia base material c. Pengujian Impak hasil:

Dari pengujian impak Charpy didapatkan

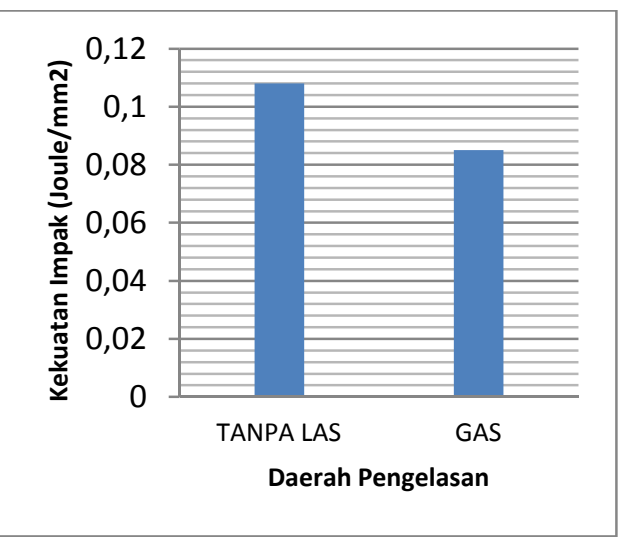

\section{Gambar 3 . Diagram Kekuatan Impak Daerah Lasan}

Dari diagram diatas didapatkan bahwa ketangguhan dari hasil uji impak, material yang mengalami proses pengelasan Oksi-Asitelin memiliki kekuatan impak 0.085 Joule $/ \mathrm{mm}^{2}$. Kekuatan impak dari proses pengelasan OksiAsitelin masih dibawah dari kekuatan impak base material yang tanpa mengalami proses pengelasan yaitu sebesar $0.108 \mathrm{Joule} / \mathrm{mm}^{2}$. 


\section{d. Uji Struktur Mikro}

Dari foto mikro didapatkan:

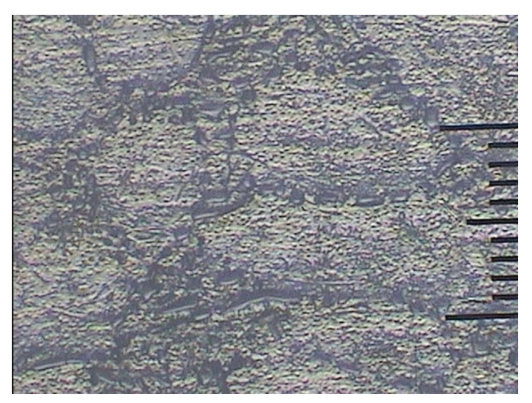

base material

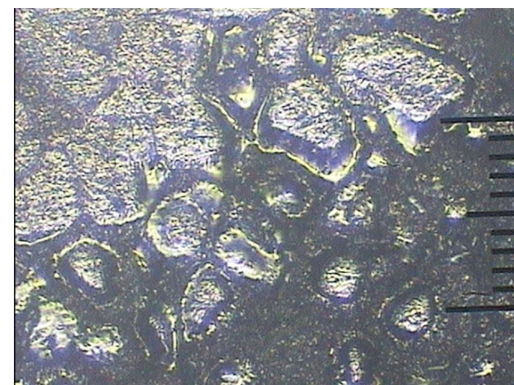

daerah sambungan (HAZ) Oksi-Asitelin

\section{Gambar 4. Hasil Uji Struktur Mikro}

Tampak pada gambar bahwa didaerah sambungan (HAZ) kristal-kristal Si berukuran lebih kecil dibandingkan dengan kristal Si pada base material karena pada daerah tersebut terjadi pendinginan lebih cepat. Hal ini akan mempengaruhi nilai kekerasan pada daerah sambungan (HAZ) tersebut. Bisa dikatakan pada daerah tersebut memiliki nilai kekerasan yang lebih rendah dari base material maupun logam lasan.

\section{KESIMPULAN}

1. Kekerasan hasil pengelasan OksiAsitelin, adalah $54.80 \mathrm{HBN}$, sedangkan untuk daerah sambungan las (HAZ) Las Oksi-Asitelin memiliki kekerasan 38.69 HBN, kekerasan tersebut masih lebih rendah dibandingkan dengan nilai kekerasan base material yaitu sebesar $59.59 \mathrm{HBN}$.

2. Kekuatan impak hasil pengelasan OksiAsitelin adalah 0.085 Joule $/ \mathrm{mm}^{2}$, sedangkan kekuatan impak base material sebesar 0.108 Joule $/ \mathrm{mm}^{2}$.

3. Nilai kekerasan dan kekuatan impak base material masih lebih tinggi dibandingkan dengan material yang mengalami proses pengelasan Oksi-Asitelin.

4. Dari pengamatan struktur mikro hasil proses pengelasan Oksi-Asitelin, pada daerah sambungan (HAZ) dapat dilihat kristal-kristal Si berukuran lebih kecil dibandingkan dengan kristal Si pada base material karena pada daerah tersebut terjadi pendinginan lebih cepat sehingga pada daerah tersebut memiliki nilai kekerasan yang lebih rendah dari base material maupun logam lasan.

\section{DAFTAR PUSTAKA}

Aljufri, 2008. Pengaruh variasi sudut kampuh V tunggal dan kuat arus pada sambungan aluminium Mg5083 Terhadap Kekuatan Tarik Hasil Pengelasan TIG, Thesis USU Medan

Balasubramanian. V, Ravisankar. V, Madhusudhan Reddy. G, "Effect of pulsed current welding on fatigue behavior of high strength aluminium alloy joints", Science Direct. Materials and Design 29 (2008) 492-500

Bambang Pr. 2006,"Pengaruh penggunaan jenis fluks pembungkus elektroda dan varian arus listrik pengelasan terhadap kekuatan tarik pada plat baja EMS -45 dengan kampuh $V$, UNS Surakarta

D.J. Tillack. 2007.“Welding superalloys for aerospace applications”, Welding Journal, pp.28-32 
IN Budiarsa. 2008, "Pengaruh Besar Arus Pengelasan dan Kecepatan Volume Alir Gas Pada Proses Las GMAW terhadap Ketangguhan Aluminium 5083” Jurnal Ilmiah Teknik Mesin CAKRAM vol.2 no.2 Desember 2008

Surasno, 2008 Pengaruh Masukan Panas pada Las Aluminium 2023 T3, Berita Teknologi Bahan dan Barang Teknik No.22

Suharno,2008. Prinsip-Prinsip Teknologi dan Metalurgi Pengelasan Logam, UNS Press Surakarta

Wiryosumarto, Harsono dan Okumura, T. 2006. Teknologi Pengelasan Logam. Jakarta: PT Pradnya Paramita.

www.welding.com, diakses tanggal 27 Desember 2011

www.weldingengineer.com, diakses tanggel 27 Desember 2011 